\title{
Atherosclerotic Descending Aortic Aneurysms. Pros and Cons of Surgery
}

\author{
Krylov Vladimir Petrovich', Titov Leonid Petrovich², Gaiduk Valentina Nikolaevna1, \\ Reut Leonid Ivanovich1', Smaliakou Aleksey Leonidovich', \\ Mankevich Nadezhda Vladimirovna ${ }^{1}$ \\ ${ }^{1}$ Republican Scientific and Practical Centre "Cardiology", Ministry of Health of Belarus, Minsk, Belarus \\ ${ }^{2}$ Republican Scientific and Practical Centre "Epidemiology and Microbiology", Ministry of Health of Belarus, \\ Minsk, Belarus \\ Email: fun-69@yandex.ru, leonidtitov@tut.by
}

Received 3 September 2015; accepted 13 September 2015; published 16 September 2015

Copyright (C) 2015 by authors and Scientific Research Publishing Inc.

This work is licensed under the Creative Commons Attribution International License (CC BY). http://creativecommons.org/licenses/by/4.0/

(c) (i) Open Access

\begin{abstract}
Within the last few years, there has been a strong trend to rethink the issue of management of atherosclerotic descending thoracic and abdominal aortic aneurysms (AAAs). When etiopathogenetic associations among changes observed during the progression of the disease were not fully described, surgeons had successfully applied, although traumatic, but a rather radical method to rescue from the rupture threat. As we gained experience and knowledge about long-term outcomes, mostly concerned mortality, we realized that surgery could not be the main tactical approach to AAAs treatment due to its frequent inefficiency and failure to guarantee that the disease would be suppressed including co-morbidities, polymorphic processes and clinical manifestations. It all required more sparing treatment strategies. The situation gave rise to a more argumentative and sparing medical-and-surgical approach to treatment based on a more in-depth understanding of the etiopathogenesis of the disease whereas surgery would remain of prime importance when appropriate. The following has been developed to improve treatment outcomes for AAA: 1) Multifactorial determination of indications for surgical correction with outlining the area of relative and absolute risk of aneurysm rupture; 2) Method of conservative treatment aimed to attain and maintain optimal blood pressure, target levels of cholesterol and low-density lipoproteins, as well as reduce oxidative and inflammatory processes in aorta, strengthen its wall, stabilize the disease and control co-morbidities. A four-year follow-up of patients using this developed technology has yielded more preferred results suggesting the need for narrowing indications for surgery to treat AAAs. Another advantage of the sparing approach to treat AAA is economic, due to fewer operations and implantations of stent-grafts, considering the fact that medical treatment should be used in operated subjects, too.
\end{abstract}

\section{Keywords}

Aneurysms, Descending Thoracic and Abdominal Aorta, Indications for Surgery, Surgical,

How to cite this paper: Petrovich, K.V., Petrovich, T.L., Nikolaevna, G.V., Ivanovich, R.L., Leonidovich, S.A. and Vladimirovna, M.N. (2015) Atherosclerotic Descending Aortic Aneurysms. Pros and Cons of Surgery. World Journal of Cardiovascular Surgery, 5, 91-101. http://dx.doi.org/10.4236/wjcs.2015.59015 


\section{Conservative Treatment}

\section{Introduction}

National Russian Abdominal Aortic Aneurysm Management in Adults Guidelines [1] indicate that the only and most persuasive justification for operative intervention to treat abdominal aortic aneurysm is prevention of its rupture that may be fatal. This argument made Russian experts reduce aortic diameter in which the patient would be subject to operative treatment which is $5 \mathrm{~cm}$ for men and $4.5 \mathrm{~cm}$ for women.

And still few specialists consider the treatment of AAA to be surgical [2], although the presence of multiple concomitant somatic diseases increases ever high death rates in individuals who undergo aortic prosthesis operations up to $32 \%-60 \%$ [3] [4]. Even endovascular methods of AAA treatment, which are the alternative to conventional surgery, cannot dramatically solve the problem.

Worldwide and national trials show that treatment techniques for individuals with abdominal and thoracic aortic aneurysms are far from perfect [5] [6], which is not surprising as most of the investigators only analyze options for surgical treatment discarding the fact that one third of AAA subjects cannot be operated due to a variety of reasons. Moreover, high rates of co-morbidities are neglected which frequently result in death, even more frequently than aneurysm rupture itself; and despite surgery, a proportion of patients show aneurysm rupture [1] [7]-[9]. Therefore, the issue becomes more therapeutic than surgical.

Many investigators consider it feasible to use wait-and-see approach with permanent monitoring, echo and CT control and multiple conservative treatments [1] [10] when the size of aneurysm is below $5.5 \mathrm{~cm}$. It is well known, however, that small-sized aneurysms (diameter between 37 and $40 \mathrm{~mm}$ ) may rupture, too, especially if untreated. Above all, AAA is not regarded as multifactorial etiopathogenetic condition, but as an impaired mechanical pathway, which needs surgical repair.

Large randomized trials to comparatively assess open operative interventions and endovascular treatment methods have confirmed suspicions about inefficient invasive methods [11]-[13]. Thus, the search of brand new options for treatment and correction of pathological changes at early stages of aneurysm development is now a crucial issue for medical science [14].

Recently, new works have appeared to reconsider and complement our knowledge about AAA etiopathogenesis. More authors talk about the combination of atherosclerotic, inflammatory and dysplastic changes occurring in aorta to be an aggregate cause of their development [14]-[17]. They underline the role of connective tissue display as a predictor of structural and functional changes in large arteries [17].

The autoimmune concept of aneurysm development has found ever more followers and has been confirmed in a variety of experimental and clinical and laboratory studies. Blood serum of AAA subjects shows a broad number of autoantibodies to endothelial cell, smooth muscle cell, collagen and elastin cell antigen determinants. Patients demonstrate antiphospholipid antibodies and IgE \& IgG4-producing plasma cells [18]. Interactions between autoantibodies and antigen-specific T-lymphocytes, and corresponding aortic wall antigens induce immunoinflammatory response in vascular walls attended by migration, adhesion and infiltration of all layers of aorta with neutrophiles, monocytes/macrophages [19] [20], dendritic and mast cells [21], and B- and T-lymphocytes [22] [23]. Activation signals (microbial products, immune complexes, proinflammatory cytokines, and bioactive complement protein fragments) produced on cell components result in the activation, synthesis and secretion of a broad number of molecular products including free radicals, cytokines, metalloprotease, chymase, and cytokines [24] [25]. It results in a dramatic inflammatory intensification, impaired structural and functional aortic integrity, accompanied by enlarged aortic fragment. The process progression results in the sudden rupture [26] [27].

Our understanding of immune inflammatory molecular and cellular mechanisms in the settings of AAA is still incomplete and requires a more profound study of the role of some components and a combination of factors responsible for the progression of malignant processes and protective factors. Moreover, a search of effective therapeutic modalities that will block main inflammatory steps and factors as well as technologies of remodeling of aortic wall structure and functions is of the academic interest.

Recently, new data have been described about the efficacy of medical treatment and potential options to surgical treatments of AAAs [8] [9] [14] [15]. Therefore, at present we may surely declare that not every aneurysm 
may be operated but every aneurysm needs treatment.

Study aims: To define main causes of the disease progression and the onset of fatal outcome in descending aortic aneurysm (DAA) and compare results of active surgical and sparing treatment modalities.

\section{Materials and Methods}

A retrospective study was conducted in the period between 2010 and 2011 including 63 patients with DAA treated in cardiosurgical clinic, and between 2011 and 2015 including 200 patients with the same disease treated in the settings of counseling service.

The diagnosis of DAA was made based on standard diagnostic criteria: descending aortic diameter increased to more than $30 \mathrm{~mm}$ confirmed by US or CT (CT angiography) or aortography data.

Clinical inclusion criteria of the study were:

- patients with confirmed DAA subjected and not subjected to surgical treatment;

- patients with/without arterial hypertension who had signed informed consent form to enter into the study.

Exclusion criteria were:

- patients with other organ abnormalities at terminal stage;

- patients with Marfan syndrome.

These 63 in-patient subjects treated in surgical department were analyzed using standard method (Group 1). Among them, 56 underwent operation: 50-aorta prosthesis operation and 6 received a stent-graft. Seven individuals received no operation due to a high risk associated with co-morbidities.

A total of 200 patients were analyzed using sparing treatment standardized, premodified and approved scheme in outpatient clinic settings in which surgery was used only when there was a threat of rupture [8] [9]. Among these, 121 patients had a 2-year follow-up (Group 2) and 99 patients had a 4-year follow-up (Group 3). Patients with the 4-year follow-up were divided into 2 subgroups: those showing favorable (3.1) and unfavorable (3.2) course of the disease. Survival and reasons for fatal outcomes were analyzed in all patients.

\section{Methods}

1) Clinical studies, including CT angiography, aortic angiography, coronary angiography, and US studies;

2) Surgical treatment: aorta and iliofemoral bifurcation prosthesis and endovascular stent-graft implantation;

3) Pharmacological (including antibacterial and anti-inflammatory) therapy aimed at aortic wall strengthening was provided using sparing treatment only if there was a threat of rupture and no contraindications. The combination of ACE inhibitors with amlodipine, beta-blockers and statins was given permanently. Macrolide antibiotics (roxithromycin, azithromycin), as well as symptomatic treatment were given as courses, when signs of inflammatory process appeared (C-reactive protein more than $5 \mathrm{mg} / \mathrm{l}$ );

4) Statistical analysis using parametric and nonparametric criteria: Mann-Whitney U-test and Spearman coefficient test.

\section{Results}

In all patients on sparing treatment the wait-and-see practice and antihypertensive therapy to attain target BP level of 130/80 mm Hg was used. Blood pressure, lipid levels, C-reactive protein, and aneurysm diameter were monitored once every 6 months. Surgeries were performed in aneurysm diameter above $55 \mathrm{~mm}$, obvious pain syndrome or rapid enlargement of aneurysm diameter by more than $5 \mathrm{~mm}$ at 6 months. In standard surgical approach, in the absence of contraindications, the intervention was performed when aneurysm diameter exceeded $45 \mathrm{~mm}$. Analyses of patients with DAA showed no statistically significant differences in age, sex, aneurysm diameter, including those above and below $50 \mathrm{~mm}$, their extension, diameter values of thoracic and abdominal area, and in their proportion to each other (Table 1).

At the same time, differences in the proportion of small, average and large aneurysms were seen. Thus, percentage of patients with aneurysms with the diameter $<50 \mathrm{~mm}$ in Group 3 was statistically higher compared to Group 1. It is due to the patient referral to hospitalization for surgical treatment and therefore the majority of small aneurysms were excluded. Moreover, a reverse statistically significant difference in average aneurysms was observed. Group 3 showed statistically bigger aneurysms as they included all inoperable aneurysms over the 4-year follow-up period. For this reason, this group may not be considered an easy group as for the physical condition. 
Table 1. Comparison of common features between three DAA groups.

\begin{tabular}{|c|c|c|c|c|}
\hline Indices & Surgical approach & Sparing treatment & Sparing treatment & $P$ \\
\hline No. of patients & $\mathrm{n}=63$ & $\mathrm{n}=121$ & $\mathrm{n}=99$ & \\
\hline Follow-up period & 2 yrs. & 2 yrs. & 4 yrs. & \\
\hline Age & $62.4 \pm 0.97$ yrs. & $67 \pm 0.77 \mathrm{yrs}$ & $66.6 \pm 0.89$ yrs. & $>0.05$ \\
\hline M & $60(95.2 \%)$ & $107(88.4 \%)$ & $86(86.9 \%)$ & $>0.05$ \\
\hline Abdominal aortic aneurysm & $52(82.5 \%)$ & $91(75.2 \%)$ & $76(76.8 \%)$ & $>0.05$ \\
\hline Descending thoracic aortic aneurysm & $11(17.5 \%)$ & $30(24.8 \%)$ & $23(23.2 \%)$ & $>0.05$ \\
\hline Abdominal aortic aneurysm diameter (in $\mathrm{mm}$ ) & $48.4 \pm 2.22$ & $43.97 \pm 2.41$ & $44.1 \pm 1.7$ & $>0.05$ \\
\hline Descending thoracic aortic aneurysm (in mm) & $44.5 \pm 2.03$ & $48.9 \pm 2.64$ & $52.1 \pm 2.6$ & $>0.05$ \\
\hline Patients with small aneurysms, $\mathrm{d}<50 \mathrm{~mm}$ & $30(47.6 \%)$ & $70(57.85 \%)$ & $66(66.7 \%)$ & $>0.051-3$ \\
\hline Patients with average aneurysms, $d=50-69 \mathrm{~mm}$ & $26(41.3 \%)$ & $45(37.2 \%)$ & $16(16.2 \%)$ & $>0.051-3$ \\
\hline Patients with large aneurysms, $d>70 \mathrm{~mm}$ & $7(11.1 \%)$ & $6(4.95 \%)$ & $17(17.2 \%)$ & $<0.052-1 \& 3$ \\
\hline $\mathrm{L}$ of aneurysms in $\mathrm{mm}$ & $87.8 \pm 5.33$ & $85.1 \pm 5.4$ & $86.9 \pm 5.1$ & $<0.05$ \\
\hline
\end{tabular}

The development of DAA is accompanied by a number of co-morbidities, suggesting that they may become a marker of multiple organ failure not only relative to the age of these patients but probable similarity to their origin and pathogenesis (Table 2).

As seen from Table 2, all groups are almost consistent in frequency of certain co-morbidities irrespective of age, sex or follow-up period.

Typically, DAA patients demonstrate stenosis of coronary and brachiocephalic arteries with various severities of coronary and cerebral circulatory disorders. In a proportion of patients this combination necessitates coronary or bracheocephalic plasty or refusal from operative treatment due to a high risk of fatal outcome [3] [5].

Almost every fourth individual was diagnosed with diabetes mellitus (24.2\%), whereas renal diseases and CKD were often seen in conservatively treated patients (34.3\%). The next more severe diseases were seen in patients with cancers $(9.1 \%)$ in which they were a primary cause of death.

We have made a comparison of the study results (age, descending thoracic aortic/abdominal aneurysm diameter and length, BP, lipid profile, CRP), co-morbidities (cancer, CKD, DM, gout), and assessment of compliance shown by those operated and treated medically and died due to aneurysm rupture and other diseases. Statistical analysis has shown no differences across the parameters except compliance that was 2 times lower in patients with aneurysm rupture compared to death for other reasons.

At the same time, CRP values and aneurysm diameter and length in these patients were close to the margin of significant difference. Based on this, it was assumed that the key factors for the progression of DAA might include structural condition of aortic wall, inflammatory process and noncompliance.

Patient management and the results are shown in Table 3.

In sparing management, surgical intervention was provided in only $14 \%$ of patients of Group 2 and $24.2 \%$ in Group 3. Vast majority of patients $(88.9 \%$ ) of Group 1 (active surgical management) received operation. Fifty patients received aorta prosthesis operation and six patients were implanted with stent-graft. Seven patients received no operation due to the severity of the disease determined by co-morbidity.

In Group 2 and Group 3 ( $24 \%$ and $22.2 \%$ patients, respectively) patients were not operated due to the severity of the disease, and it is 2 times more than in Group $1(11.1 \%)$. More than half of patients on sparing treatment without co-morbidities were not operated due to a small aneurysm size and because the progression of the disease might be suppressed medicamentally. Even though the correlation exists between aneurysm diameter and the threat of rupture, statistical analysis has shown that ruptures may occur when the diameter is below $40 \mathrm{~mm}$, which we observed three times in clinical settings. The cause was inflammatory process.

Even though the statistical analysis information capacity is subdued, the unidirectionality of changes is clear. The more evident are mortality rates. As [8] [9] we mentioned the comparison of mortality rate seen in Group 1 and Group 2 which was $20.6 \%$ for active surgical approach, and $9.92 \%$ for sparing management.

Hazard ratio (HR) for 2-year mortality in these groups was calculated using the following method [28]: planning, processing and reporting of data obtained from biomedical testing using SAS System-HR $=13 \backslash 11: 50 \backslash 110$ $=2.62$ (first ratio is for patients who died, and the second ratio is for survivors). Consequently, when us 
Table 2. Incidence of co-morbidities in DAA patients.

\begin{tabular}{cccc}
\hline Co-morbidity & Group 1, $\mathrm{n}=63$ & Group 2, $\mathrm{n}=121$ & Group 3, $\mathrm{n}=99$ \\
\hline Arterial hypertension & $82.5 \%$ & $81.0 \%$ & $83.8 \%$ \\
CHD & $72.5 \%$ & $77.8 \%$ & $67.7 \%$ \\
Atherosclerosis of lower extremities & $36.2 \%$ & $36 \%$ & $34.3 \%$ \\
Atherosclerosis of bracheocephalic artery & $32.5 \%$ & $23.9 \%$ & $28.3 \%$ \\
Diabetes mellitus & $27.3 \%$ & $13.3 \%$ & $24.2 \%$ \\
Renal disorders & $16.25 \%$ & $23.9 \%$ & $34.3 \%$ \\
Cancer & $5 \%$ & $7.7 \%$ & $9.1 \%$ \\
Gout & $2 \%$ & $11.9 \%$ & $7.0 \%$ \\
COPD & $1.25 \%$ & $2.2 \%$ & $3.0 \%$ \\
\hline
\end{tabular}

Table 3. Comparison of DAA patient management and mortality rates when using active surgical treatment and medicated correction with operative treatment was provided only in case of threat of rupture.

\begin{tabular}{|c|c|c|c|}
\hline Indices & Group $1, \mathrm{n}=63$ & Group 2, $\mathrm{n}=121$ & Group $3, \mathrm{n}=99$ \\
\hline Follow-up period & 2 yrs. & 2 yrs. & 4 yrs. \\
\hline Management approach & Surgical & Sparing & Sparing \\
\hline \multirow[t]{2}{*}{ Operated, including stent-graft implantation } & $56(88.9 \%)$ & $17(14.0 \%)$ & $24(24.2 \%)$ \\
\hline & 6 & 8 & 8 \\
\hline Non-operated, including due to severity of & $7(11.1 \%)$ & $104(86.0 \%)$ & $75(75.8 \%)$ \\
\hline the disease & $7(11.1 \%)$ & $29(24.0 \%)$ & $22(22.2 \%)$ \\
\hline Mortality rate among operated pts., & $8(14.3 \%)$ & $1(0.83 \%)$ & $5(20.8 \%)$ \\
\hline including that not associated with the operation & $4(7.14 \%)$ & - & $3(12.5 \%)$ \\
\hline Mortality rates among non-operated pts. & $5(71.4 \%)$ & $11(10.6 \%)$ & $18(24 \%)$ \\
\hline Mortality rate due to aneurysm rupture, & $4(6.35 \%)$ & $4(3.3 \%)$ & $8(8.1 \%)$ \\
\hline - Among operated pts. on aorta & $2(3.57 \%)$ & - & $2(8.3 \%)$ \\
\hline - Among non-operated pts. & $2(28.6 \%)$ & $4(3.85 \%)$ & $6(8 \%)$ \\
\hline Mortality rate due to other diseases, & $7(11.1 \%)$ & $7(5.8 \%)$ & $13(13.1 \%)$ \\
\hline - Among operated pts. on aorta & $4(7.14 \%)$ & - & $1(4.2 \%)$ \\
\hline - Among non-operated pts. & $3(42.86 \%)$ & $7(6.7 \%)$ & $12(16 \%)$ \\
\hline All-cause mortality & $13(20.6 \%)$ & $12(9.92 \%)$ & $23(23.2 \%)$ \\
\hline
\end{tabular}

ing $95 \%$ confidence interval (CI) its upper and lower limits are 1.99 and 11.3 , respectively. It suggests that mortality ratio in Group 2 is 2.6 times lower than in Group 1. It means that survival rate in sparing management is significantly higher than in active surgical approach.

All-cause mortality in Group 3 was $23.2 \%$, which is virtually consistent with double value of mortality seen in Group 2 (9.92\%), as if doubles up the 2-year mortality value. It is also consistent with the 2-year result (20.6\%) in Group 1 (active surgical management) despite the differences seen during the follow-up. Mortality rates in operated patients were $14.3 \%$ for Group 1, $0.83 \%$ for Group 2, and 20.8\% for Group 3. In half of the cases it was not associated with operation itself, but with other reasons.

Mortality rates among non-operated patients were $71.4 \%$ for Group 1, 10.6\% for Group 2, and 24\% for Group 3. Mortality in Group 1 was high because seven patients had severe co-morbidity which had resulted in aneurysm rupture in 2 patients, and death due to other disease in three patients. Two patients were treated medicamentally. 
Mortality rates due to aneurysm rupture were 2 times higher in Group 1 than in Group $2(6.35 \%$ \& 3.3\%, respectively), and it was $8.1 \%$ in Group 3 which is consistent with doubling the value of 2 -year follow-up for Group 2. In Group 1 and Group 3 two operated patients died as a result of aneurysm rupture. Mortality rate related to other diseases showed the same ratio between groups related to aortic rupture; two patients of Group 1 and 1 patient of Group 3 related to other disease.

The analysis of mortality in one group at 4 years has shown that it was at its highest in non-operated patients and was $24 \%$ (18 patients) but among these, only six patients had aneurysms rupture, and 12 died of other disease, and all of these individuals had clear contraindications to operation. Mortality value was almost consistent with that seen in the operated patients and made up 20.8\%. In Group 3 and Group 1, it was because patients who had had surgery died of aneurysm rupture, other diseases or as a result of operation, even though they were more somatically safe.

The next position in the mortality analysis belongs to co-morbidities which were $13.1 \%$ followed by aneurysm rupture which was $8.1 \%$ and for which the surgical approach of DAA management exists.

Data obtained from the analysis suggest the presence of significant discrepancies between mortality causes and current DAA management approaches. Thus, we divided Group 3 into two subgroups by favorable course (without progression of aneurysm size) which included 26 patients and unfavorable course (with $5 \mathrm{~mm}$ increase of aneurysm diameter at 6 months) which included 33 patients (Group 3.1 and Group 3.2, respectively). A comparison between 67 study parameters was made using nonparametric criteria, i.e. Mann-Whitney U-Test and Spearman correlation coefficient.

Forty patients out of 90 were not included in these subgroups. These were the subjects who died immediately after the follow-up started, and those who had large aneurysm $(>70 \mathrm{~mm})$ at baseline; those operated at the start of follow-up period and fully noncompliant patients who had been lost to follow-up despite numerous attempts to invite them to examinations who had only baseline aneurysm diameter.

Clinical and functional comparison of patients with favorable и unfavorable course is shown in Table 4. Statistical analysis has shown high level of significance $(P<$ between 0.05 and 0.00001$)$ by nine parameters specified in Table 4. The greatest level of significance was defined by CRP, aneurysm diameter and length, and atherogenic index $(\mathrm{AI}), \mathrm{BP}$ and compliance.

As seen from Table 4, baseline CRP $<2.7 \mathrm{mg} / \mathrm{l}$, aneurysm diameter $<36.3 \mathrm{~mm}$, aneurysm length $<63.3 \mathrm{~mm}$, $\mathrm{AI}<2.68, \mathrm{LDL}<2.7 \mathrm{mmol} / \mathrm{l}, \mathrm{BP}<132.4 / 78.6 \mathrm{~mm} \mathrm{Hg}$ and present compliance suggest the favorable course.

Unfavorable course of the disease is defined by baseline DAA diameter $>44.3 \mathrm{~mm}$, length $>81 \mathrm{~mm}, \mathrm{CRP}>$ $8.3 \mathrm{mg} / \mathrm{l}, \mathrm{AI}>4.05, \mathrm{LDL}>3.46 \mathrm{mmol} / \mathrm{l}$ and $\mathrm{BP}>142.1 / 86.77 \mathrm{~mm} \mathrm{Hg}$ that collectively reflect the high risk of further progression of the disease. Among these factors, only aneurysm diameter and length might be corrected surgically. All other factors require immediate and targeted medical treatment, especially CRP, as it is the most evident sign of DAA unfavorable course.

Therefore, a combination of active drug therapies is administered during six months or more. If during aggressive drug therapy aneurysm stops enlarging and positive dynamics is noted making the indices close to baseline seen for favorable course, it means that the patient has a relative risk. In this case the follow-up and

\section{Table 4. Comparison of Subgroup 3.1 and Subgroup 3.2.}

\begin{tabular}{|c|c|c|c|}
\hline \multirow[b]{2}{*}{ Factors affecting DAA } & \multicolumn{3}{|c|}{ Unfavorable course, $n-33$} \\
\hline & High risk & Relative risk & $\begin{array}{c}\text { Favorable course, } \\
n-26\end{array}$ \\
\hline Baseline CRP & $>8.3 \mathrm{mg} / 1$ & failure to attain $2.7 \mathrm{mg} / 1$ after treatment & $<2.7 \mathrm{mg} / 1$ \\
\hline Baseline d DAA & $>44.3 \mathrm{~mm}$ & negative trend absent & $<36.3 \mathrm{~mm}$ \\
\hline Baseline L & $>81 \mathrm{~mm}$ & negative trend absent & $<63.3 \mathrm{~mm}$ \\
\hline $\mathrm{L}$ after treatment & $>90.57 \mathrm{~mm}$ & negative trend absent & $<61.3 \mathrm{~mm}$ \\
\hline Baseline AI & $>4.05$ & failure to attain 2.7 after treatment & $<2.68$ \\
\hline LDL after treatment & $>3.46 \mathrm{mmol} / 1$ & failure to attain $2.7 \mathrm{mmol} / 1$ after treatment & $<2.7 \mathrm{mmol} / 1$ \\
\hline $\mathrm{BP}_{\text {syst. }}$ after treatment & $>142.1 \mathrm{~mm} \mathrm{Hg}$ & failure to attain $132.4 \mathrm{~mm} \mathrm{Hg}$ after treatment & $<132 \mathrm{~mm} \mathrm{Hg}$ \\
\hline $\mathrm{BP}_{\text {diast. }}$ after treatment & $>86.77 \mathrm{~mm} \mathrm{Hg}$ & failure to attain $78.6 \mathrm{~mm} \mathrm{Hg}$ after treatment & $<78.6 \mathrm{~mm} \mathrm{Hg}$ \\
\hline Compliance & none & poor & present \\
\hline
\end{tabular}


drug therapy may proceed.

If drug therapy fails to attain baseline values for favorable course of DAA (CRP, lipid profile and BP) and aneurysm enlargement persists, the risk of rupture becomes critical and requires open aortic prosthetic reconstruction surgery or stent-graft implantation. Our experience shows that DAA patients treated medicamentally tolerate operative treatment well. This approach reduces risks of aneurysm rupture that allows doctors to refrain from operations or perform them only in critical circumstances thus increasing the probability of success.

Based on these results, we have revised diagnostic and treatment approach to treat DAA:

1) Baseline CRP $<2.7 \mathrm{mg} / \mathrm{l}$; aneurysm diameter $<36.3 \mathrm{~mm}$; aneurysm length $<63.3 \mathrm{~mm}$; AI $<2.68$; $\mathrm{LDL}<$ $2.7 \mathrm{mmol} / \mathrm{l} ; \mathrm{BP}<132.4 / 78.6 \mathrm{~mm} \mathrm{Hg}$ and present compliance, the follow-up is continued with state control every 6 - 12 months accompanied by symptomatic therapy;

2) Baseline aneurysm diameter $>44.3 \mathrm{~mm}$; CRP $>8.3 \mathrm{mg} / \mathrm{l}$; AI $>4.05$; LDL $>3.46 \mathrm{mmol} / \mathrm{l}$; $\mathrm{BP}>$ $142.1 / 86.77 \mathrm{~mm} \mathrm{Hg}$, unfavorable course is defined with patient switched to dynamic monitoring with control of lipid profile, C-reactive protein value, antihypertensive therapy efficacy and compliance level every 3 months; and aneurysm diameter control (US, CT or MPT) every 6 months;

3) Antihypertensive therapy is administered using b-blockers, ACE inhibitors, calcium antagonists with targeted BP level of more than 110/70 and less than 135/80 mm Hg; azithromycin is administered with targeted level of CRP $<2.7 \mathrm{mg} / \mathrm{l}$; statins are administered with targeted level of lipid spectrum-LDL less than $2.4 \mathrm{mmol} / \mathrm{l}$, $\mathrm{AI}<2.68$

4) Physical exercise is limited;

5) Co-morbidity treatment is provided at all stages;

6) In the absence of negative dynamics for DAA, baseline diameter $>44.3 \mathrm{~mm}$, baseline length $>81 \mathrm{~mm}$, and length after treatment $>90.57 \mathrm{~mm}$, and approximation of other indices to baseline, patients may be considered as having relative risk of unfavorable course at 3 - 6 months with continuation of drug therapy;

7) If drug therapy is ineffective or results in deterioration of baseline characteristics of unfavorable DAA, indications for surgery are defined.

\section{Discussion}

We failed to follow-up the group with active surgical approach over a 4 year-period, as more than half of patients were lost to contact and we could not properly classify them. However, we can observe that this group still has problems as DAA is still apparent, and the number of co-morbidities is naturally increasing. We not only see them but also continue medical correction of both progressive DAA and co -morbidities.

Currently, the indications to operation include the achievement of aneurysm diameter of more than $55 \mathrm{~mm}$ in men and $52 \mathrm{~mm}$ in women, its enlargement by more than 5mm at 6 months [1] [3] [5]-[7] [29], and as some authors believe, the fact of aneurysm detection itself [2]. Disadvantage of these indications is the absence of ethiopathogenetic features of aneurysm formation, and only metric criteria of its state are considered but it does not reflect the processes occurring in the wall. It does not favor to drug therapy enhancement to suppress the DAA progression. Unjustified operations may result in additional risk for patients, as well as moral and economic losses [3] [5] [8] [9].

Pathomorphological studies have shown that DAA is characterized by aortic media thinning accompanied by smooth muscle vascular attenuation and extracellular matrix destruction determined by inflammation, oxidative stress and proteolysis, as well as by the formation of minor intramural thrombi inducing impaired endothelial integrity [30] [31]. Endothelial cells play a key role in maintained vascular integrity, inflammation and thrombosis control, as well as mural cells and matrix component. Endothelial cell apoptosis is associated with the activation (formation) of thrombin, platelet adhesion and clotting resulting in impaired trophism (metabolism) of vascular wall components and reduced vascular wall thickness [32]. Simultaneously, patients with DAA demonstrate increased levels of endothelial cell precursors in peripheral circulation that indirectly suggest both their rapid formation in bone marrow, and their demand seen in lesions [33].

Circulating endothelial cells are characterized by a number of surface markers including CD31+ (platelet endothelial cell adhesion molecule PECAM-1), sialomucin (mucosialin) molecule CD34, transforming growth factor receptor molecule or endoglin CD105, vascular endothelial cadherin CD144, laminin receptor (Muc18) CD146, tyrosine kinase receptor (Tie2) CD202b, and vascular endothelial growth factor receptor-2 CD309 [33]. Detection of the abovementioned factors allows for a detailed analysis of endothelial cell or precursor content 
and immunophenotype in patients and standardization of cell cultures when cell therapy is provided.

The model of DAA endovascular therapy using mature aortic endovascular cells seems promising as it enhances aortic reendothelization, inflammation control, exchange of regenerative processes accompanied by stronger vascular wall and reduced risk of aortic rupture, and the usage of autologous stem cells found in bone marrow, adipose tissue or peripheral blood to restore a layer of smooth muscle fibers [34] [35] and strengthen the aortic wall. In this case we may see the inhibition of enzymes destroying elastin. Recovery of smooth muscle cells result in enhanced elastin synthesis and formation of elastin fiber network that surround aortic wall.

Intravenous immunoglobulins are used to suppress inflammatory response and produce immunomodulating effects [36]. Some authors recommend intravenous immunoglobulins G for DAA patients, as they inhibit inflammatory response, eliminate microbial antigens and produce immunomodulating effects on B- and T- lymphocytes. A complex of methods of nonsurgical treatment of DAA, thus, can be markedly extended, especially for cases when surgery is contraindicated. Global trends in population ageing make this issue highly topical.

Comparison of intergroup mortality rates among operated and nonoperated patients has shown that the results of active surgical approach are evidently more modest compared to sparing approach to treat DAA. Even Groups who received sparing approach showed better effects of drug therapy than those who underwent surgery, even though aneurysm rupture occurs much less frequently than death due to co-morbidities $(8.1 \%$ \& $13.1 \%$, respectively). This difference becomes 2-fold or more if added mortality rates after surgical intervention.

Our survival data for patients with DAA [8] [9] suggest that the use of sparing approach may bring better results than surgery. Over a 2-year follow-up, survival in patients on sparing treatment was $90.08 \%$, and $76.8 \%$ over a 4-year follow-up.

Hertzer N.R. [37] provides some different data obtained from the follow-up of 1135 individuals. Survival was $67 \%$ at 3 years and $39 \%$ at 5 years. A randomized English and American trial investigating a group of nonoperated patients (UK Small Aneurysm Trial and ADAM) showed survival that was $64 \%$ in aortic diameter between 4.9 and $5.5 \mathrm{~cm}$ at 4.6 years. Nikolsky [38] and Paul [39] indicate that $65.2 \%$ of patients survive at 3 years.

Russian National Guidelines [1] indicate a 5-year survival after surgery based on Schwartz et al. and Faggioli et al. to be $40 \%-50 \%$ depending on aneurysm site.

\section{Conclusions}

We are in search for the best possible DAA treatment options. Analysis and comparison of the results, opinions, and overall assessment of well-known and newly obtained data on etiopathogenesis of aortic atherosclerosis allow for a development of combined medical and surgical treatment for this group of patients.

National Russian Abdominal Aortic Aneurysm Management in Adults Guidelines [1] address the prevention of aneurysm fatal rupture as the one and only justification for its operative treatment. This argument encouraged Russian specialists to lower the threshold value of aortic diameter subjected to operative treatment, which was 5 $\mathrm{cm}$ for men and $4.5 \mathrm{~cm}$ for women.

Still, many experts consider the treatment of DAA a surgical issue [2], although the presence of co-morbidities increases death rates after aortic prosthesis operations to $32 \%$ - 60\% [4] [5] [7]. Even endovascular treatment modalities being the alternative to conservative surgical approach cannot offer a dramatic solution to the problem.

Our comparison of two modalities shows the need for narrowing indications for operative treatment of DAA. Conservative treatment aimed at maintaining optimal BP, targeted cholesterol and low-density lipoproteins and decreasing of oxidative and inflammatory processes in aorta, as well as strengthening its wall, stabilization of the course of disease and control of co-morbidity has yielded promising results.

There is an additional advantage of sparing approach to treat DAA, which is cost-effective, as costs of surgery, prosthetics and stent-graft implantation stably surpass expenditures for medical treatment provided for operated patients. Our experience has shown that such pharmacological modality is needed at each step of the treatment even in minor aneurysms. Moreover, it should be considered that more than one third of DAA patients cannot be operated due to co-morbidity, threshold age and baseline abnormal lesion unsuitable for operation. They also require adequate operative treatment.

To improve outcomes of treatment for DAA, the following has been developed:

1) Multifactorial determination of indications for surgical correction outlining the area of relative and absolute risk of aneurysm rupture. Baseline diameter $>44.3 \mathrm{~mm}$, length $>81 \mathrm{~mm}, \mathrm{CRP}>8.3 \mathrm{mg} / \mathrm{l}, \mathrm{AI}>4.05$ and $\mathrm{BP}>$ 
142/87 mm Hg as well as noncompliance suggest a great risk of aneurysm rupture requiring 3 - 6 month etiopathogenetic treatment. Present uncorrectable negative trends suggest the progression of the disease and are the indication for surgery.

2) Method of conservative treatment aimed at maintaining optimal BP, targeted cholesterol and low-density lipoproteins and decreasing of oxidative and inflammatory processes in aorta, as well as strengthening its wall, stabilization of the course of disease and control of co-morbidity.

A four-year follow-up for this group of patients based on our technology shows promising results and needs further implementation.

\section{References}

[1] National Russian Abdominal Aortic Aneurysm Management in Adults Guidelines (2011) National Russian Abdominal Aortic and Lower Axtremity Aneurysm Management in Adults Guidelines: Russian Consensus Paper. Bakulev RCCVS RAMN, Moscow, 140.

[2] Chervyakov, Y.V. and Smurov, S.Y. (2011) Management to Treat Abdominal Aorta. Grekov vestnik Khirurgii, 170, 57-61.

[3] Bokeria, L.A. and Arakelyan, V.S. (2010) Surgery to Treat Thoracic and Thoracoabdominal Aortic Aneurysms: Doctors Handbook. Bakulev RCCVS RAMN, Moscow, 394.

[4] Zakhariev, T., et al. (2001) Combined Surgical Treatment of Patients with Multifocal Atherosclerosis. Khirurgiia, 57, 14-23.

[5] Belov, Y.V. and Komarov, R.N. (2010) Our Failures and Methods to Reduce In-Hospital Mortality Rates in Operative Treatment of Thoracoabdominal Aortic Aneurysms. Angiology and Vascular Surgery, 1, 105-112.

[6] Shirinbek, O. (2008) Infrarenal Aneurysms of Abdominal Aorta: Current Management and Outcomes (Literature Review) in Russian. Cardiovascular Diseases: Bakulev RCCVS RAMN Bulletin, 9, 50-57.

[7] Belov, Y.V., Komarov, R.N., Stepanenko, A.B., Gens, A.P., et al. (2008) Step-by-Step Management of Aortic Aneurysms. Khirurgiya, 3, 17-24. http://www.mediasphera.ru/journals/pirogov/detail/409/6025/

[8] Krylov, V.P., Mrochek, A.G., Titov, L.P., Gaiduk, V.N., Reut, L.I. and Smaliakou, A.L. (2014) Can We Change a Look at Atherosclerotic Aortic Aneurysm Treatment? Health, 6, 1345-1351.

[9] Krylov, V.P., Gaiduk, V.N., Yanushko V.A., Reut L.I., Mankevich, N.V., Smaliakou, A.L, Mikhnevich V.B. and Dergachyova I.M. (2014) Ways to Improve Therapeutic Efficacy in Patients with Atherosclerotic Descending Aortic Aneurysms. Cardiologia v Belarusi, 33, 5-16.

[10] Lederle, F.A., Wilson, S.E., Johnson, G.R., et al. (2002) Aneurysm Detection and Management Veterans Affairs Cooperative Study Group. Immediate Repair Compared with Surveillance of Small Abdominal Aortic Aneurysm. The New England Journal of Medicine, 346, 1437-1444.

[11] EVAR Trial Participants (2005) Endovascular Aneurysm Repair versus Open Repair in Patients with Abdominal Aortic Aneurysm (EVAR Trial 1): Randomized Controlled Trial. The Lancet, 365, 2179-2186. http://www.ncbi.nlm.nih.gov/pubmed/15978925

[12] EVAR Trial Participants (2005) Endovascular Aneurysm Repair and Outcome in Patients Unfit for Open Repair of Abdominal Aortic Aneurysm (EVAR Trial 2): Randomized Controlled Trial. The Lancet, 365, 2187-2192.

https://ueaeprints.uea.ac.uk/14186/ http://dx.doi.org/10.1016/S0140-6736(05)66628-7

[13] Isselbacher, E.M. (2005) Thoracic and Abdominal Aortic Aneurysms. Circulation, 111, 816-828. http://circ.ahajournals.org/content/111/6/816.full http://dx.doi.org/10.1161/01.CIR.0000154569.08857.7A

[14] Mikhailov, D.V., Vinokurov, I.A., Bogopolskaya, O.M., et al. (2011) Perspectives of Preventive Treatment of Aneurysms of Large Vessels. Cardiologia i serdechnososudistaya khirurgiya, 1, 51-56. http://www.mediasphera.ru/uppic/Cardsurg/2011/1/10/KSS_2011_01_51.pdf

[15] Cherepakhin, D.I., Bazilev, V.V., Evtyushkin, I.L., et al. (2012) Aneurysms of Large Vessels in the Era of Genomics and Proteomics, and Options of Prognostic Medicine. Cardiologia i serdechnososudistaya khirurgiya, 5, 58-62. http://www.mediasphera.ru/journals/cardsurg/detail/874/14140/

[16] Nikonenko, A.A. and Trylin, A.V. (2013) The Role of Cyclophilin A in Pathogenesis of Abdominal Aortic Aneurysm. Cardiologia i serdechnososudistaya khirurgiya, 6, 39-42. http://www.mediasphera.ru/journals/cardsurg/detail/1100/17821/

[17] Martinov, A.I., Gudilin, V.A., Drokina, O.V., et al. (2015) Endothelial Dysfunction in Patients with Connective Tissue 
Dysplasia. Lechaschiy vrach, 2, 18-21. http://www.lvrach.ru/2015/02/15436157/

[18] Kasashima, S. and Zen, Y. (2011) IgG4-Related Inflammatory Aortic Aneurysm. Current Opinion in Rheumatology, 23, 18-23. http://dx.doi.org/10.1097/BOR.0b013e32833ee95f http://journals.lww.com/co-rheumatology/Abstract/2011/01000/IgG4 related inflammatory abdominal aortic.5.aspx

[19] Ghiglotti, G., Barisione, C., Garibaldi, S., Brunellei, C., Palmieri, D., Spinella, G., Reme B., Spallarosa, P., Alieri, P., Fabei, P., Sambuceti, G. and Palombo, D. (2013) CD16+ Monocytes Subsets and Increased in Large AAA and Are Differently Related with Circulating and Cell-Associated Biochemical and Inflammatory Biomarkers. Disease Markers, 34, 131-142. http://dx.doi.org/10.1155/2013/836849

[20] Samadzadeh, K., Chun, K., Nguyen, A., Baker, P., Bains, S. and Lee, E. (2014) Monocytes Activity Is Linked with Abdominal Aortic Aneurysms Diameter. Journal of Surgical Research, 190, 328-334. http://dx.doi.org/10.1016/j.jss.2014.03.019

[21] He, A. and Shi, G. (2015) Mast Cells Tryptase as Targets for Cardiovascular and Methabolic Diseases. Current Pharmaceutical Design, 19, 1114-1125.

[22] Lv, B.-J., Li, J.Y. and Cheng, X. (2014) T-Lymphocytes and Aortic Aneurysms. Life Science, 57, 795-801. http://dx.doi.org/10.1007/s11427-014-4699-X

[23] Jevallee, H., Tang, T. and Cheng, X. (2011) Regulatory T-Cells and Cardiovascular Diseases. North American Journal of Medicine and Science, 4, 178-182. http://dx.doi.org/10.7156/v4i4p178

[24] Wang, J., Chen, J., Chen, C., Huang, S., Rao, X. and Zhong, J. (2012) Elevated Th17 and IL23 in Hypertensive Patients with Acutly Increased Blood Pressure. American Journal of Immunology, 8, 27-32.

http://dx.doi.org/10.3844/ajisp.2012.27.32 http://thescipub.com/PDF/ajisp.2012.27.32.pdf

[25] Liao, M., Liu, C., Ly, B., Zhang, J., Cheng, L., Cheng, X., Lindhole, J., Rassmussen, L. and Shi, G. (2015) Plasma Cytokine Levels and Risks of AAA: A Population Based Prospective Cohort Study. Annals of Medicine, 47, $245-252$. http://informahealthcare.com/doi/abs/10.3109/07853890.2015.1019916

[26] Lindholt, L. and Shi, G. (2006) Chronic Inflammation, Immune Response and Infection in AAA. European Journal of Vascular and Endovascular Surgery, 31, 453-463. http://dx.doi.org/10.1016/j.ejvs.2005.10.030 http://www.sciencedirect.com/science/article/pii/S1078588405006994

[27] Ramaswamy, A., Hamilton, M., Joshi, R., Kline, B., Li, R., Wang, P. and Goergen, C. (2013) Molecular Imaging of Experimental Abdominal Aortic Aneurysms. The Scientific World Journal, 2013, 1-18. http://dx.doi.org/10.1155/2013/973150

[28] Plavinsky, S.L. (2005) Planning, Processing and Reporting of the Results Obtained from Biomedical Studies Using SAS. Biostatistika, SPb MAPO, 559. (In Russian)

[29] Kemma, A., John, Thomas, L.F. and Serrius Patrick, V. (2011) Cardiovascular Disease Edition. "ESC Guidelines" GEOTAR-Media, 1209-1248. (In Russian)

[30] Allaire, E., Schneider, F., Saucy, F., Dai, J., Cochennec, F., Michineau, S., Zidi, M., Becquemin, J.P., Kirsch, M. and Gervais, M. (2009) New Insight in Aetiopathogenesis of Aortic Diseases. European Journal of Vascular and Endovascular Surgery, 37, 531-537. http://dx.doi.org/10.1016/j.ejvs.2009.02.002

[31] Kazi, M., Thyberg, J., Religa, P., et al. (2003) Influence of Intraluminal Thrombus on Structural and Cellular Composition of Abdominal Aortic Aneurysm Wall. Journal of Vascular Surgery, 38, 1283-1292. http://www.jvascsurg.org/article/S0741-5214(03)00791-2/abstract http://dx.doi.org/10.1016/S0741-5214(03)00791-2

[32] Bombeli, T., Karsan, A., Tait, J.F. and Harlan, J.M. (1997) Apoptotic Vascular Endothelial Cells Become Procoagulant. Blood, 89, 2429-2442. http://www.ncbi.nlm.nih.gov/pubmed/9116287

[33] Yoder, M. (2010) Is Endothelium the Origin of Endothelial Projenitor Cells? Arteriosclerosis, Thrombosis, and Vascular Biology, 30, 1094-1103. http://atvb.ahajournals.org/content/30/6/1094.full

[34] Yamawaki-Ogata, A., Hashizume, R., Fu, X.-M., Usai, A. and Narita, Y. (2014) Mesenchymal Stem Cells for Treatment of Aortic Aneurysms. World Journal Stem Cells, 6, 278-287. http://dx.doi.org/10.4252/wjsc.v6.i3.278

[35] Tian, X., Fan, J., Yu, M., Zhao, Y., Fang, Y., Bai, S., Hou, W. and Tong, H. (2014) Adipose Stem Cells Promote Smooth Muscle Cells to Secrete Elastin in Rat AAA. PLOS ONE, 9, e108105. http://journals.plos.org/plosone/article?id = 10.1371/journal.pone.0108105

[36] Newberger, J.W., Takahashi, M., Gerber, M.A., Gewitz, M.H., Tani, L.Y., et al. (2004) Diagnosis, Treatment, and Long-Term Management of Kawasaki Disease. Circulation, 110, 2747-2771.

http://dx.doi.org/10.1161/01.CIR.0000145143.19711.78 http://www.ncbi.nlm.nih.gov/pubmed/15505111

[37] Hertzer, N.R., Young, J.R., Beven, E.G., et al. (1987) Late Results of Coronary Bypass in Patients with Infrarenal Aor- 
tic Aneurysm. Annals of Surgery, 205, 360-367. http://dx.doi.org/10.1097/00000658-198704000-00004 http://www.scopus.com/record/display.url?eid=2-s2.0-0023254629\&origin=inward\&txGid=926C4CA9CC751DF3D3 AB15B309886228.iqs8TDG0Wy6BURhzD3nFA\%3a7

[38] Nikolsky, E. and Mehran, R. (2004) Impact of Symptomatic Peripheral Arterial Disease on 1-Year Mortality in Patients Undergoing Percutaneous Coronary Interventions. Journal of Endovascular Therapy, 11, 60-70.

http://www.ncbi.nlm.nih.gov/pubmed/14748627 http://dx.doi.org/10.1177/152660280401100108

[39] Paul, E.N. and Eikelboom, J.W. (2004) Peripheral Arterial Disease: Prognostic Significance and Prevention of Atherothrombotic Complications. Medical Journal of Australia, 181, 150-154. https://www.mja.com.au/system/files/issues/181 03 020804/nor10045 fm.pdf 